\title{
ROLE AND WORK STYLE OF THE MANAGER NURSES FOR SUCCESSFUL CONFLICT MANAGEMENT IN THE HOSPITAL
}

\author{
Violeta Tsvetanova
}

Prof. Dr. Ivan Mitev Branch of Medical University - Sofia, Vratsa

\begin{abstract}
INTRODUCTION: The health care management in hospitals is assigned to the members of the Health Care Council - the chief nurse and the senior nurses. These managers, supported by their high level of professionalism, skills and knowledge, can lead the planning, organization, coordination, motivation, evaluation and control of the activities of the health care professionals. The effective management of emerging conflicts depends on the position, style and approach of the chief nurse and senior nurses.
\end{abstract}

AIM: To establish how the roles of the management staff in the Health Care Council influence the team performance, including the successful management in hospital wards.

MATERIALS AND METHODS: The study was conducted in the period April 2015 - February 2016 at the Hristo Botev Hospital, Vratsa using the Belbin psychometric test.

STUDY SUBJECTS: Twenty-five senior health care professionals and the chief nurse. The study used a sociological method of analysis.

RESULTS AND DISCUSSION: One of the great benefits of the HCC teamwork is in the fact that the people complement each other and everyone contributes with what he/she can do best. According to the Belbin psychometric test the eight team roles accurately describe the specific work adjustments and behaviors of people in the HCC team.

\section{ROLES IN THE AUDIT TEAM:}

Strong roles: Teamworker, Coordinator, Completer Finisher

Weak roles: Resource Investigator and Plant

Missing representatives of strong roles in the team: Resource Investigator

Category of the team: Rather a good team

Problematic areas for team performance: Generating new ideas

Leadership: Not successful enough

RECOMMENDATIONS: One of the recommendations is effective recruitment of management staff in the HCC. In order to prevent conflicts, the leader should recognize the personality type of each associate and use that knowledge to motivate them to give the best of themselves.

Keywords: Health Care Council, team role, management style

Address for correspondence:

Violeta Tsvetanova

Prof. Dr. Ivan Mitev Branch of Medical University - Sofia

Student Complex 1

3000 Vratsa

e-mail:wioletta_tz@abv.bg 
Violeta Tsvetanova

\section{INTRODUCTION}

The health care management in hospitals is assigned to the members of the Health Care Council, which consists of the chief nurse and the senior health care professionals in the wards. These managers, supported by their high level of professionalism, skills and knowledge, can lead the planning, organization, coordination, motivation, evaluation and control of the activities of the health care professionals. The manager nurses' competence and professionalism are crucial for the proper health care management.

Health care managers' activities are complex and require various personal qualities. It is impossible to combine these qualities in one person and because of that the team is necessary. Therefore, the tool, which ensures successful dealing with conflicts in the health care professionals' practice, is not a single person, but the team. The team should not look for people with perfectly matched characteristics, but appropriate separate persons who are able to fulfill complementary roles. The manager nurse team (the members of HCC) is compound and its successful functioning requires a balance between different team roles.

The team structure is one of the first important steps in building an effective working group. The team members should be combined as roles and as characters and they have to fit together, because this is the fundament of good working group establishment. Dr. Belbin has developed a self-assessment questionnaire that is useful both in the formation of the team and its evolution and improvement. The test is an appropriate source of self-knowledge and a basis for understanding both own preferences and behavior in the group, and others in the team.

\section{AIM}

The aim of this study is to determine how the roles of the management staff in the Health Care Council impact the team efficiency, including the successful conflict management in the hospital wards.

\section{GOALS}

1. To audit the HCC team in order to determine if the necessary team roles are present and if its structure is sufficiently balanced;
2. To analyze the data from the Belbin psychometric test in order to determine the team efficiency;

3. To study the profile of the entire team and individual profiles in order to determine the personal contribution of each one to the teamwork;

4. To develop and identify correct actions.

\section{SUBJECT AND OBJECT OF THE STUDY}

The subject of the study is the HCC team's efficiency.

The object are the members of the Health Care Council of the Hristo Botev Multi-profile Hospital For Active Treatment in Vratsa - the chief nurse and 25 senior health care professionals.

\section{MATERIALS AND METHODS}

Sociological method - survey of collecting, summarizing and analyzing information concerning opinions and evaluations by the valid, anonymous, individual psychometric test of M. Belbin.

Graphic analysis of the results - to illustrate the studied variables and their interrelations. We have used column, sector and other charts for this purpose as well as software package Microsoft Office Excel 2010 in order to make the graphics.

Analytical analysis of the results - for analysis of the study data.

Study duration and place: The study was conducted in the period April 2015 - February 2016 at the Hristo Botev Hospital in Vratsa using the Belbin psychometric test.

The questionnaire identified eight roles in the team - Implementer, Teamworker, Completer Finisher, Monitor Evaluator, Shaper, Coordinator, Plant, and Resource Investigator. It consisted of seven sections, each of them including eight statements, which were related to the team/group work style. For each of the seven sections there were ten points among the possible answers, which were used to describe the behavior of the studied person. Belbin's purpose was to create effective technique for team establishment. He accomplished his goal in the 1980s with the development of a team roles model (Belbin, 1981). Belbin suggested that understanding the team role within a particular team, everyone can develop their 
strengths and manage their weaknesses as a teammate and can improve the way that he / she contributes to the effectiveness of the team. Belbin's model is used by many organizations, including companies from FTSE-100 (the one hundred companies in Great Britain, which have the biggest market share), multinational agencies, governmental authorities and consultants and it has been translated into 16 languages (Aritzeta, 2007).

\section{RESULTS}

The study included 25 senior health care professionals - nurses, a midwife, an X-ray technician, and clinical laboratory assistants, who work in wards with diagnostic, therapeutic, surgical, intensive and emergency orientation, maternity and pediatric focus and the chief nurse at the Hristo Botev Hospital in Vratsa. The Belbin test was distributed at an HCC meeting of the senior executives. They were instructed on how to fill out the test and what the method of determining the team roles was.

Table 1 presents the sociodemographic characteristics of senior executives from the HCC of the Hristo Botev Hospital in Vratsa.

The share of nurses who have EQD Master of Health Care Management is considerable (Table 1), including the chief nurse (38.46\%) and $19.23 \%$ of health care managers have EQD Bachelor of Health

Table 1. Sociodemographic characteristics of HCC members

\begin{tabular}{|c|c|c|c|}
\hline Basic Characteristics & & Number & Relative share \% \\
\hline \multirow{7}{*}{ Age group } & Under 30 years & 0 & $0.00 \%$ \\
\hline & $31-40$ years & 1 & $3.84 \%$ \\
\hline & $41-50$ years & 10 & $38.46 \%$ \\
\hline & $51-60$ years & 13 & $50.00 \%$ \\
\hline & Over 60 years & 2 & $7.69 \%$ \\
\hline & Total & 26 & $100 \%$ \\
\hline & Chief nurse & 1 & \\
\hline \multirow{2}{*}{$\begin{array}{l}\text { Office and position in the } \\
\text { organizational hierarchy }\end{array}$} & Senior nurses /midwife, laboratory assistant/ & 25 & \\
\hline & Total & 26 & $100 \%$ \\
\hline \multirow{7}{*}{$\begin{array}{l}\text { Educational Qualification } \\
\text { Degree }\end{array}$} & Master of Health Care Management & 10 & $38.46 \%$ \\
\hline & Bachelor of Health Care Management & 5 & $19.23 \%$ \\
\hline & Bachelor of Health Care & 5 & $19.23 \%$ \\
\hline & Health Care Specialist & 5 & $19.23 \%$ \\
\hline & College & 1 & 3.84 \\
\hline & Other & 2 & \\
\hline & Total & 26 & $100 \%$ \\
\hline \multirow{5}{*}{ Work experience } & Up to 5 years & 1 & $3.84 \%$ \\
\hline & $5-10$ years & 1 & $3.84 \%$ \\
\hline & $11-15$ years & 2 & $7.69 \%$ \\
\hline & $16-20$ years & 2 & $7.69 \%$ \\
\hline & Over 20 years & 20 & $76.92 \%$ \\
\hline \multirow{5}{*}{$\begin{array}{l}\text { Experience as a senior health } \\
\text { care manager }\end{array}$} & From 1 to 5 years & 5 & $19.23 \%$ \\
\hline & From 6 to 10 years & 5 & $19.23 \%$ \\
\hline & $11-15$ years & 6 & $23.07 \%$ \\
\hline & $16-20$ years & 5 & $19.23 \%$ \\
\hline & Over 20 years & 5 & $19.23 \%$ \\
\hline
\end{tabular}


Violeta Tsvetanova

Care Management. This result is standard, because it is stated in the MIL that it is obligatory to have this education in order to be employed at this position. Two of the managers have also a second higher education degree - Master of Economics and Master of Public Health and Health Management. The data shows that desire for career development and motivation of HCC members for additional qualification are high. Unfortunately, one third of the senior executives have EQD, which does not comply with the MIL requirements. But these people were hired due to lack of specialists with the necessary education (mostly diagnostic specialties). Despite the wide educational opportunities there are still management positions, which are held by managers without proper education.

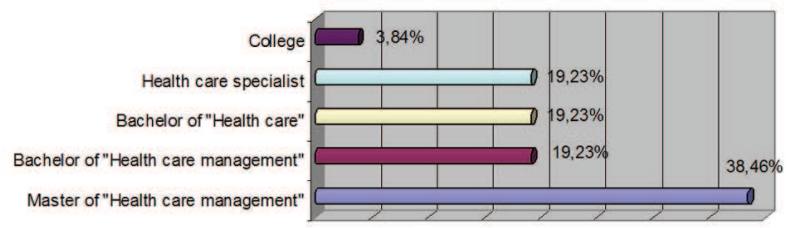

Fig. 1. Allocation of senior managers by EQD.

The average age of respondents is 51 years, and the relative share of the 51-60 years age group is the highest $-50.00 \%$. After analyzing the respondents by age, it was established that the larger percentage in the study went to the senior nurses in pre-retirement age, due to relation of career fulfillment with the advance in years of professional experience. This lead to thinking that the HCC team would suddenly be replaced by many people with less work experience.

From the studied $26 \mathrm{HCP}$ managers /the chief nurse and the 25 senior nurses/ we determined the following role team personalities (Fig. 2):

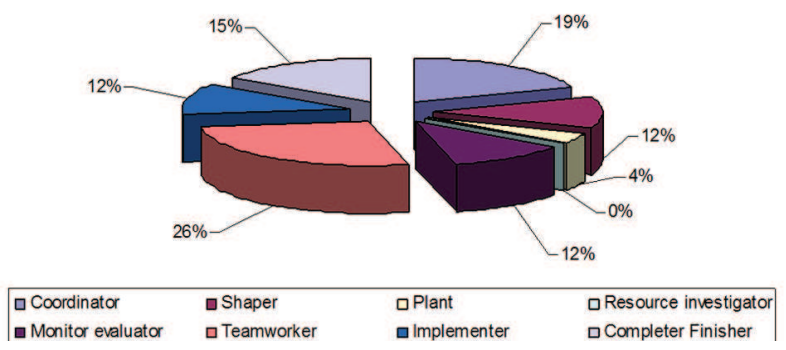

Fig. 2. Allocation of the senior managers by team role personality type
1. According to the performed HCC team role, the chief nurse's personality type is Monitor Evaluator - an intelligent, stable introvert, who can objectively consider the problems and conflicts and makes the right decisions. She can prepare a proper strategy about innovation implementations in nursing practice and foresee conflict situations. She can assess all the possibilities and ways to solve these problems. She decides rightly and unemotionally, because she is a serious and prudent person. Disadvantages: She lacks energy and ability to inspire the others. She is too critical. It should be noted that for the successful conflict solving in the nursing practice it is very important for the chief nurse to be leader and coordinator. In this case, the leader role is replaced with administering. There are two persons, among the 25 manager nurses, who have the personality type of a Monitor Evaluator, i.e. 11.53\% of the management team. All of these personality types have EQD Master in Health Care Management and have work experience as managers of over 20 years.

2. The highest percentage at the Hristo Botev Hospital is the personality type Teamworker $26.93 \%$. They are stable extroverts, cooperative, receptive and diplomatic. They listen carefully, prevent frictions, calm the others down and can successfully cope with conflict situations. They are eager to help their colleagues and are ready to support good proposals. This is an approach in which both sides seek to maximize the satisfaction of both their and other's interests, showing trust and openness. This approach is at the heart of the most effective methods for solving conflicts through negotiation and mediation. The Teamworkers are indecisive, when they are under pressure and stress and are easily influenced by others. The study shows that the more senior nurses with EQD, which do not meet the requirements for appointment to this position are Teamworkers.

3. The share of the senior nurses, who possess the personality type Coordinator - stable, dominant extroverts, confident, well organized and good managers is $19.24 \%$. They can clarify the goals, encourage decision taking and delegate tasks. They can motivate the ordinary nurses 
and their colleagues from HCC and help them reveal their secret talents. They are unifying persons, who can influence the others. The Coordinators are valuable in resolving conflicts in nursing practice. They will certainly clarify the different positions and will move towards the effective conflict resolution. Sometimes they may seem manipulative and often delegate personal tasks. For employees in the age group of 51-60 years, and managers with over 20 years of experience the role of Coordinator is more typical than for those with less work experience.

4. Four of the manager nurses $/ 15.39 \% /$ have the role of - Completer Finisher - restless introverts, self-organized and exigent; conscientious, looking to find mistakes and omissions. They finish their tasks on time and pay attention to the details. But in their ambition to accomplish everything perfectly, they often cause conflict and tension between team members. The Completer Finishers tend to worry unduly and manage others in the team with reluctance. Sometimes they might be overly pedantic and intolerant of the unorganized people. In fact, these are the people who we actually need to grab the job and we will be sure that it is done well, most likely they will make innovations. But the Completer Finisher will be rude to anyone who does not respect deadlines. In many cases, these individuals go far in their careers. If they soften their natural impatience, they can become great leaders. Otherwise, they can often be a cause of conflict. This style can be the reason that external conflicts pass into direct confrontation and a clash of the forces. In the most cases the manager using this style is concerned about the attitude, which the others show and tries to look as the winner in all situations.

5. The same percentage is shared by the following two personality types - Shaper and Implementer $-11.53 \%$. The Shaper is restless, active, dominant extrovert. He is provocative, dynamic and feels good when working under pressure. He has the energy and courage to take risks and surmount difficulties. The Shaper can achieve success in his work as a senior manager, but this is at the expense of human relationships within the team. He can focus the group on the purpose, he is individualist by nature and achieves excellent results, but usually alone. The Shaper can provoke the other people and hurt their feelings. He easily loses patience with people who act more slowly. Very often these relationships are the reason for conflicts between teammates. Typical of the Shaper role is that most are senior executives, who are aged between $41-50$ years.

6. Three of the senior nurses have the role of an Implementer $/ \mathbf{1 1 . 5 3 \% / . ~ T h e y ~ a r e ~ c o n s e r v a - ~}$ tive, disciplined, reliable and expeditious. They convert the ideas into practical actions. They approach the tasks systematically and prefer more practical solutions than the new ideas. They older nurses who have more work experience are this type. They are less likely to take risks and are somewhat inflexible and slow to respond to the new opportunities. Sometimes they may be intolerant to people who are less expeditious or systematic. In some cases they can be in conflict with the management in the implementation of the innovations. But once they realize the benefits, this type of people can be very useful in the practical organization and implementation of management decisions. All three nurses have EQD Master of Health Care Management.

7. One of the senior nurses is the personality type Plant $/ 3.84 \%$ / - she invents original ideas and has a creative mind. She has the ability to make connection between ideas, which are hard to connect. She is serious and independent, introverted, highly sensitive, which can make her feel uncomfortable if she thinks she causes a problem or conflict within the team. If her ideas receive rejection, she can alienate herself and refuses to participate.

8. After the performed survey we found that in the HCC team there is no one with the personality type of Resource Investigator - extrovert. Someone who can take the interesting ideas from the others and develop them further. Someone who has the ability to explore different opportunities. Someone who has a wide network of contacts; who can sell an interesting idea. The Resource Investigator is an opti- 
Violeta Tsvetanova

Table 2. Summary of the team study

\section{Type of the studied team}

Count of the audit team members

Status of the team balance

Strong team roles

Weak team roles

Missing representatives of powerful roles in the team

Team category

Problematic areas for team performance

Leadership

mist, who loses interest once the initial enthusiasm passes. She/he is someone who can be intolerant towards introverted personalities or towards people, who pays attention to the details.

Below (Fig. 3) the balance of the management structure from the HCP in the studied hospital is presented. The individual role profiles of the chief nurse and all 25 senior nurses are graphically depicted.

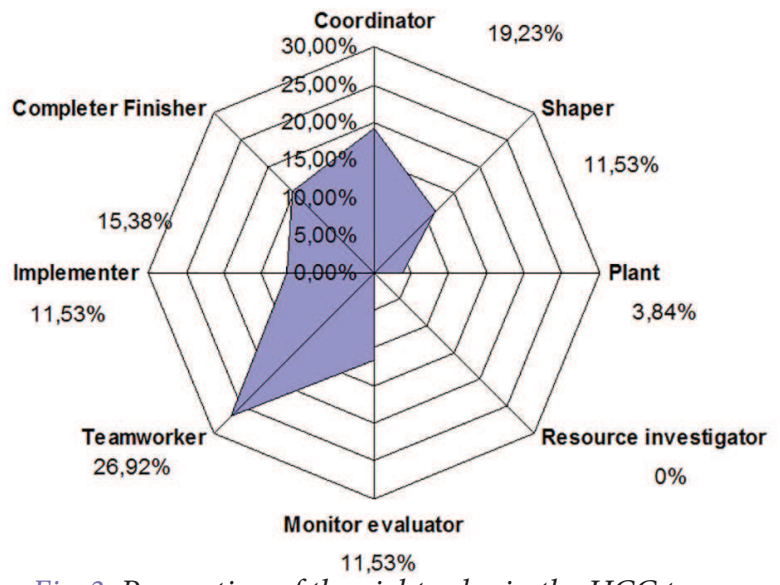

Fig. 3. Proportion of the eight roles in the HCC team. State of the team balance

The figure shows us that the Teamworker and Coordinator roles definitely dominate in the management nurse team. However, at the same time there is a lack of the role of Resource Investigator and there is only one person who has the Plant role. In other words, the HCC team is unbalanced.

\section{DEDUCTIONS}

1. It follows from the study that the manager nurse team will be relatively successful in most
Managing - Health Care Council of the Hristo Botev

Hospital, Vratsa

The Chief nurse and 25 senior health care professionals

Disbalance

Teamworker, Coordinator, Completer Finisher

Resource Investigator and Plant

Resource Investigator

Rather a good team

Generating new ideas

Not successful enough areas of its activity - creating the appropriate organization of work, performing tasks, assigned by management.

2. At the same time, the HCC team will suffer from lack of fresh and original ideas as well as suggestions for new methods of working. This is a serious problem, because of situation of permanent changes and reforms, it is necessary to suggest new ideas.

3. The largest percentage in the team roles in HCC goes to Teamworker and Coordinator, which leads to the conclusion that there are enough working behaviors, closely connected with conducted negotiations in order to reach an agreement about the goals, the tasks, the implementation deadlines and the resources. There are enough seniors, who can operate in order to reach a consensus in conflict resolving.

4. The chief nurse, as the HCC team leader, has to work on the qualities of a Coordinator, which can help her combine her work as a good manager and as a leader. One of the main rules for the prevention of conflicts is the ability of the manager to recognize the personality type of each collaborator from the beginning in order to cope with him. The manager should lead the hospital attendants in an inspiring way, which can make them give the best of themselves.

\section{CONCLUSION}

The eight team roles according to the Belbin psychometric test describe very precisely the specific work attitudes and behaviors of the people in the HCC team at the Hristo Botev Hospital in Vratsa. 
Role and Work Style of the Manager Nurses for Successful Conflict Management in the Hospital

Usually, everyone has one or two strong roles, so he/ she has several moderate and weak roles. The strong and weak roles of the people have been established so that each teammate can focus on that, which he/she can do best.

The conflicts in the teams are the result of the fact that people differ from one another and their behaviors, attitudes and perceptions are different and often clash with somebody else's perceptions. Like any other group, the HCC team at the Hristo Botev Hospital, Vratsa may also oberve contradictions and conflicts. They are resolved with the mutual goal in mind. The established system of rules and regulations, whose followers are all members of the team, assists to make this. Therefore, one of the great benefits of teamwork consists in that the people are complementary to one another and in this way everyone contributes to what he/she can do best. All this represents a kind of a team culture, which provides high efficiency in achieving the goals, facing the HCC.

The recommendations for maintaining an effective team consist mainly of the following:

1. Frequent auditing of the teams in the wards in the Hristo Botev Hospital in Vratsa.

2. Effective recruitment of management staff in HCC in order to create balance in the strongest qualities and abilities of members.

3. In order to prevent conflicts the leader should recognize the personality type of each associate and should use that knowledge to motivate them to give the best of themselves.

4. Through appropriate approaches and tools to ensure confidence in the behavior of the team. There should be a focus on enhancing the competence of the team members.

5. Challenges and responsible tasks should be presented to every member of the team, taking into account the results.

Abbreviations:

HCC - Health care council

EQD - Educational Qualification Degree

HC - Health care

HCM - Health care management

MIL - Medical institutions law

HCP - Health care professionals
MHAT - Multi-profile hospital for active treatment

\section{REFERENCES}

1. Andreeva M. Organizational Behavior. Sofia: Ciela; 1998. (in Bulgarian)

2. Balkanska P. Only for Managers: Mastering the Art to Manage. Health Management. 2003; 3(4):13-17. (in Bulgarian)

3. Vodenicharov Ts, Popova S. Medical Ethics. Sofia: Filvest, 2005 (in Bulgarian)

4. Kamenov K et al. A Person, Teams, Leaders. Sofia: Lyuren; 2000. (in Bulgarian)

5. Markham W. Conflict Management. Sofia: Kibea; 1999. (in Bulgarian)

6. Paunov M. Organizational Behavior. Sofia: Ciela; 1997. (in Bulgarian)

7. Stoyanov V. Organizational Psychology. Sofia: Psydo; 2005. (in Bulgarian)

8. Hristova $\mathrm{T}$ et al. The Ten Golden Rules for Working in a Team. Sofia: Ciela; 2006. (in Bulgarian)

9. Belbin M. Management Teams. Oxford; 1992.

10. Belbin M. Team Rols at Work. Oxford; 1996.

11. Deeprose D. Team Coach. N. Y.; 1995.

12. Follet M. Dynamic Administration. N. Y.; 1942.

13. Haney W. Communication and Interpersonal Relations: Text and Cases. Homewood; 1986.

14. Likert R. The Human Organization: Its Management and Value. N. Y.; 1967.

15. Margerison Ch, McCann D. Team Management Systems. Queensland; 1985

16. http:// www.belbin.com/about/belbin-team-roles/

17. http://www.managementstudyguide.com/ 